\title{
Economic Analysis "Cost of Production of Major Vegetables" In Balochistan, Pakistan
}

\author{
Jumo Khan Bajkani ${ }^{1}$, Khalil Ahmed ${ }^{2}$, Muhammad Afzal ${ }^{3}$, Nadeem Sadiq ${ }^{4}$, \\ Muhammad Nauman Irshad ${ }^{5}$ \\ The authors are respectively the ${ }^{1}$ Scientific Officer, SSRI, PARC, Sariab Quetta, ${ }^{2-5}$ Lecturer in Balochistan \\ Agriculture College Quetta, ${ }^{3}$ Director, SSRI, PARC, Sariab Quetta, and ${ }^{4}$ Senior Scientific Officer, Arid Zone \\ Research Centre, Quetta
}

\begin{abstract}
This paper describes the economic analysis of vegetables in districts Loralai, Bolan and Killa Saifullah of Balochistan with a view to determine the production cost, current production system, input-output ratio and gaps in farm practices and finally suggest the way to fill out these gaps. Total 109 respondents were interviewed from all districts. The study was conducted through primary data collection from different vegetable growers who had planted vegetable crops. The data was collected from selected vegetable growers during the crop year, 2011-12. The additionally, information was gathered the farm size, average cost of production of vegetable was separated into for categories i.e.; fixed costs, capital costs, labor costs and marketing costs in the major vegetable growing areas. The survey results showed that all the vegetable growers applied 15-20 irrigations to vegetable crops in the study area. During the survey mostly farmers reported the production decreased as compared last year due to non-proper management, electricity problem and shortage of water. Vegetable yield in the province is well below the potential.
\end{abstract}

Key Words: Economics analysis, Vegetable, Net income, Variable cost, Cost benefit ratio, Balochistan and Pakistan

\section{Introduction}

Pakistan is basically an agro based country and we are fortunate that Allah Almighty has bestowed us with rich fertile soils and best climatic conditions which is suitable for the production of not only major crops but also fruits \& vegetables. It is largely grown in Punjab and followed by other provinces in Pakistan and cultivated in Rabi and Kharif season with including potato, chilies and onion. Vegetables are a rich and comparatively cheaper source of food. They provide all the important nutrients such as, proteins, fats, starch, minerals and vitamin; thus, their daily consumption is necessary for a balanced diet. Pakistan produced a wide range of both traditional (summer and winter vegetables) and off-season vegetables. Vegetable seeds are one of the major high value agricultural produce in Pakistan. These are a major input and play a vital role in increasing the production of seasonal and off-season fresh vegetables in the country.

Vegetables are the largest produced and consumed in Pakistan. The quality of vegetables seed has direct impacts on its yield. Vegetables give higher net revenues than others crops in the area due to low costs of production and high prices of output. [1] they reported per capita consumption estimate is about $35 \mathrm{~kg}$ annually which is far below the minimum level necessary for basic nutrition. However, the growing family income is expected to increase the demand for vegetables as well. Some authors narrated that the spite of a reputation that Asian cuisine, and food habits in Asia are very much based on vegetables, most countries have a yearly per capita availability of vegetables considerably below the minimum per capita consumption requirement of 55 $\mathrm{kg} / \mathrm{caput} / \mathrm{year}$. Nevertheless, per acre yield is low mainly because shortage of water and non proper marketing mechanism. Vegetable crops have the potential to become attractive enterprise if proper attention is given to develop production and marketing infrastructure. [2] reported the farmers are achieving high returns from vegetable production. With more training, they could further increase production levels and diversify into other cash crops. For example, vegetables offer significant opportunities: Balochistan exports vegetables for 4 months a year; and imports of vegetables in our neighboring country and province like Iran and Sindh province for the rest of the year.

In Balochistan, total cropped area was 1081.3 thousand hectares, among them vegetables are produced on about 75.3 thousand hectares (Including Potato, Onion and Chilies) of land with an annual production of 1054.383 thousand tones, [3]. The average yield per hectare of vegetables is reported to be about 10-11 tones, which is very low as compared to the world standards. Vegetables are cultivated throughout the country hence their availability in the market remains round the year except for few summer months.

Vegetables play a major role in increasing household income, improving the nutritional standards and in providing employment to many Balochistan farmers. With rising incomes, population and urbanization in 
Balochistan, the domestic demand for quality vegetable is increasing with time and the production is not keeping pace with rising demand. Besides low production, vegetable production not only varies from year to year, but also varies from season to season. In Balochistan, there is acute shortage of vegetables in winter and the supplies to the market are significantly reduced because of heavy frost and cold temperatures. The objectives of this study were: to review the current status of vegetable production system, to estimate cost of production of major vegetables and to analyze the benefit-cost ratio.

\section{Research Methodology}

The study was conducted through primary data collection from vegetable growers in Balochistan province of Pakistan. A survey methodology used to collect primary data because it is commonly used in the field of social sciences. A wide range of problems can be investigated by using this approach. Survey methodology provides the plan for the study and overall framework for collected data. Survey design is an effective way to measure responses on fairly easy fashion as it uses well developed questionnaire. The methodology includes data source, study area, data collection and data analysis procedure. Finally, it ends up with the farm cost calculation of vegetable production. The primary data will be collected through farmer's interview regarding major vegetables and to quantifying the level of input and other related issues. Secondary data were collected on different variables like area production and yield of vegetable crops. Other variables were collected from various sources including, Agriculture Statistics of Pakistan, Agriculture Statistics of Balochistan and Agriculture extension. The study will be undertaken in Killa Saifullah, Loralai and Bolan districts in Balochistan. The data were gathered from 109 producers of vegetable crop, randomly selected from 25 villages. The farmers were randomly selected by chance meeting with them at the time of survey. For analysis purposes, based on farm operational holding, the sample farmers were classified into small $(\leq 12.5$ acres $)$, medium $(>12.5$ to 25 acres) and large (>25 acres) farmers categories. The gathered information was pertained to vegetable production during rabi 2011-12.

A questionnaire was developed and pretested before conducting the formal survey. The questionnaire covered information relating to the socioeconomic characteristics of the respondents like land tenure, farm size, source of irrigation and other related variables. It also included questions related to total vegetable area in 201112 , total area, input use, production practices and physical productivity. The respondents were also asked the reason for increase/decrease vegetable production in 2011-12. Farmers were interviewed personally at their farms. Before starting the interview, the researchers explained the purpose of the research and assured the respondents that all information would be confidential and be used for research purpose only. About 40 minute was required to conduct each interview.

2.1Data analysis: $\quad$ After completing the field work, the data were edited and transferred from the questionnaires into worksheet as a database file. The variable names within the database file refer to the numbers of each question in the questionnaire. To measure the performance of hybrid, improved and local vegetable varieties was carried out is based on the analysis total costs and returns. The production cost analysis is explained below.

2.2Farm Costs Analysis: The farm cost analysis is based on hybrid, improved and local vegetable varieties. The results of this study will provide for the comparison of total costs and returns of hybrid, improved and local vegetable varieties. Total costs consist of expenditure from the profit and loss account variable, fixed and opportunity costs for farm-owned factors of production. The estimation of these opportunity costs must be considered carefully because the potential income of farm owned factors of production in alternative uses is difficult to determine. In the short run, the use of own production factors on a family farm can provide flexibility in the case of low returns when the family can chose to forgone income. However, in the long run opportunity costs must be considered because the potential successors of the farmer will, in most cases, make a decision on the alternative use of own production factors, in particular their own labor input, before taking over the farm. To indicate the effects of opportunity costs, we have to separate opportunity costs from the other costs. For the estimation and calculations, following procedure is adopted to examine the performance of vegetables in Balochistan.

2.2.1Total revenue: Total revenue is the total money received from the sale of any given quantity of output. The total revenue is calculated by taking the price of the sale times the quantity sold. (Total revenue $=$ price $\mathrm{x}$ quantity) [4].

2.2.2Total costs: Total Cost is the sum of the fixed cost and total variable cost for any given level of production, i.e., fixed cost plus total variable cost. Agricultural costs are often divided into various categories. Some of the more commonly used cost concepts are as follows.

2.2.3Total fixed costs: Total fixed costs are the costs that do not change with the level of production. For example, the cost of owning a building is incurred regardless of whether the building is empty, half full, or overflowing. 
2.2.4Total variable costs: Total variable costs are the costs that change in direct proportion to changes in volume. Variable costs can be avoided by not producing. For example, the cost of feed to feed animals is a variable cost. If the animal is not purchased, no feed costs are incurred, but the fixed costs of the livestock building are still incurred.

2.2.5Opportunity costs: Opportunity costs are the cost of using a resource based on what it could have earned if used for the next best alternative. For example, the opportunity cost of farming his own land is the amount he could have received by renting it to someone else [5].

2.2.6Profit: Profit calculates by gross income minus expenses.

2.2.7Accounting profit: accounting profit is the value that remains after all expenses except opportunity costs have been subtracted from gross income. It is the same as "net farm income".

2.2.8Economic profit: economic profit is the value that remains after all costs, including the opportunity costs of the operator's labor and capital, have been subtracted from gross income. It is as same as "return to management [5].

2.2.9Gross margin: a gross margin is calculated by taking variable costs away from the gross income earned from an enterprise. Gross margins are often reported on a per rupees basis for cropping enterprises.

Gross margin $=$ returns - variable costs

2.3 Analysis of Break Even Point: The break-even point is where the total revenue equals the total cost. In other words, it is where profit equals zero. The break-even position will change according to changes in either the total costs or the total revenue. The main advantage of break-even analysis is that it points out the relationship between cost, production volume and returns. It can be extended to show how changes in fixed costs, variable cost relationships, commodity prices, and revenues, will affect profit levels and break-even points. The break-even analysis is most useful when partial budgeting or capital budgeting are to be under taking. The major benefit for using break-even analysis is that it indicates the lowest amount of business activity necessary to prevent losses [4].

2.3.1 Break-even yield: The break-even yield is the minimum yield for the farm to be profitable. The formula for computing the break-even yield is:

$$
\text { Break-even yield }=\frac{\text { Total cost }}{\text { Out put price }}
$$

This yield is necessary to cover all costs at a given output price [6]. For example, total costs (cash costs + non cash costs) $=$ Rs. 30,000/acre, output price $=$ Rs. $600 / \mathrm{mds}$. Therefore, break-even yield is $=50 \mathrm{mds} / \mathrm{acre}$.

2.3.2 Total cost $=$ Cash cost $($ variable cost + fixed cost $)+$ Non cash cost $($ depreciation + opportunity cost $)$

2.3.3 Break-even price: The break-even price is the output price needed to just cover all costs at a given output level, and can be found from the equation [6]

$$
\text { Break-even price }=\frac{\text { Total cost }}{\text { Expected yield }}
$$

For example, the break-even price would be Rs. $30,590 /$ acre divided by $632 \mathrm{mds} / \mathrm{acre}$ is equal to Rs. $48 / \mathrm{mds}$. Note that the break-even price is the same as the cost of production [7]

\section{Result And Discussion}

The main focus of this section is on the results of the survey. This section is organized into four subsections. First section deals with the socioeconomic characteristic of the sample farmers. The second section is devoted to the description of farmers' vegetable production practices during 2011-12. In the third section analyses the factors that contributed to increase/decrease vegetable yield during 2011-12. Farmers suggested measures for sustaining next year vegetable are presented in fourth section.

\section{Socioeconomic Characteristics of the Sample Respondents}

3.1 Farm Size: It is important to examine how resources are managed, and resulting impact on productivity and sustainability. The empirical literature indicated that, small farmers have an advantage in labor supervision over large farmers. Therefore, the quantity of labor inputs is likely to be higher on small farms. Second, small farmers can have restricted access to modern input, and this can hold back their productivity, third, small and large farmers may differ in their attitude to risk and uncertainty. The large farmers may be more willing and able to carry greater risk. Results showed that 50.46 percent of respondents had more than 25 acres, followed by 32.10 percent have more than $12.5-25$ acres and 17.44 percent falling less than 12.5 acres and high large, medium and small farm size was found in killa Saifullah and Bolan districts 64.29, 16.0 and 28.0 percent respectively, in table 1 . 
Table 1. Operational Land Holding of Selected Growers in 2011-12

\begin{tabular}{|l|c|c|c|c|c|}
\hline \multirow{2}{*}{ Farm size groups } & \multicolumn{3}{|c|}{ Districts } & \multirow{2}{*}{ All } & \multirow{2}{*}{$\begin{array}{c}\text { Average farm size } \\
\text { (acres) }\end{array}$} \\
\cline { 2 - 5 } & Loralai & K.Saifullah & Bolan & & 8.40 \\
\hline Small $(<12.5$ acre $)$ & $5(16.0)$ & $4(9.52)$ & $10(28.0)$ & $19(17.44)$ & 15.0 \\
\hline Medium $(>12.5-25$ acre $)$ & $8(25.0)$ & $11(26.19)$ & $16(46.0)$ & $35(32.10)$ & 55.76 \\
\hline Large $(>25$ acre $)$ & $19(59.0)$ & $27(64.29)$ & $9(26.0)$ & $55(50.46)$ & $\mathbf{3 4 . 4 2}$ \\
\hline All & $\mathbf{3 2 ( 2 9 . 3 6 )}$ & $\mathbf{4 2 ( 3 8 . 5 4 )}$ & $35(32.11)$ & $\mathbf{1 0 9 ( 1 0 0 )}$ & \\
\hline
\end{tabular}

Source: Survey data, 2011-12

3.2 Irrigation Source: Vegetable growers used different sources such as tube wells and chashma to provide first irrigation. Tube well water is mostly used at the time of scarcity of karez/chashma water. However, first irrigation is necessary to be given at crown root stage, which usually comes 3-7 days after sowing. The survey results showed that all the vegetable growers applied 15-20 irrigations to vegetable crops in the study area. The overall average source of irrigation was examined and found that 62.54 percent respondents used tube well water, 22.65 percent growers used tube well plus karez/chashma water and only 14.81 percent used chashma water as shown in table 2 .

Table 2. Source of Irrigation of Selected Growers in 2011-12

\begin{tabular}{|l|c|c|c|c|}
\hline \multirow{2}{*}{ Source of irrigation } & \multicolumn{3}{|c|}{ Farm size } & \multirow{2}{*}{ All } \\
\cline { 2 - 4 } & Small & Medium & Large & 62.54 \\
\hline Tube well & 47.37 & 65.72 & 74.54 & 14.81 \\
\hline Tube well+ Chashma & 21.05 & 14.28 & 9.09 & 16.37 \\
\hline
\end{tabular}

Source: Survey data, 2011-12

3.3 Seed Source: Quality seed is one of the important crop inputs for obtaining high yield. It is commonly believed that farmers must use pure, clean and disease free seed to obtain optimum yield. Farmers have a number of options in respect of seed source i.e. Previous crop/own seed, seed purchased from other fallow farmers, input/seed dealers and research stations. Results of study show that majority 47.78 percent of vegetable growers purchased the seed from seed dealers, 33.88 percent used their own seed from previous crop, 17.12 percent obtained from fellow farmers and only 1.21 percent growers as a source of research/extension shown in table 3.

Table 3. Seed Source of Vegetable Growers in 2011-12

\begin{tabular}{|c|c|c|c|c|}
\hline Seed source & \multicolumn{3}{|c|}{ Farm size } & All \\
\hline Fellow farmer & 15.79 & 22.85 & 12.73 & 17.12 \\
\hline Research/Extension & 0.0 & 0.0 & 3.64 & 1.21 \\
\hline
\end{tabular}

Source: Survey data, 2011-12

\subsubsection{CULTURAL PRACTICES OF VEGETABLES}

3.2.1 Sowing Time: Timely sowing of vegetable is an important factor for its rapid and successful growth. Crop sown on proper time, gave best germination of the seeds. There are two seasons in a year i.e. Rabi and Kharif. This crop is planted in October - December, which mature in 60-90 days and gives produce for more than two-three months. Kharif vegetable crop is planted in April - June and matured in 60 days. It was also observed that majority respondents did not grow the rabi vegetables crop due to shortage of water and high temperature.

3.2.2 Use of Fertilizer: It was observed that growers did not follow the recommendations made by agriculture department and mostly uses fertilizer on their own experience. Information regarding 49.54 percent respondents applied recommended dose of urea, while 38.53 percent applied above the recommended dose of urea and growers applied one bag per acre of urea after $1^{\text {st }}$ irrigation. Examined in case of DAP, in which 18.35 percent respondents did not apply DAP, 56.88 percent had applied below recommended dose, while only 17.43 percent respondents applied according to the recommended dose. Further result shows that overall average of NP was 1.83 percent growers applied below recommended dose, while 16.52 percent growers applied above 
recommended dose of NP per acre. Moreover, it was investigated that only 1.83 percent respondents used Nitrophas fertilizer below recommended dose and 16.52 percent growers applied above recommended dose, while 81.65 percent respondents did not use this fertilizer as indicated in table 4 .

Table 4. Application of Fertilizer in Vegetable during the year 2011-12

\begin{tabular}{|c|c|c|c|c|}
\hline \multirow[b]{2}{*}{ Fertilizer Doze } & \multicolumn{4}{|c|}{ Farm Size } \\
\hline & Small & Medium & Large & All \\
\hline \multicolumn{5}{|c|}{ Below recommended } \\
\hline Urea & 10.53 & 11.43 & 12.73 & 11.93 \\
\hline DAP & 73.68 & 48.57 & 56.36 & 56.88 \\
\hline NP & 0.00 & 5.71 & 0.00 & 1.83 \\
\hline \multicolumn{5}{|c|}{ Recommended } \\
\hline Urea & 78.95 & 60.00 & 32.73 & 49.54 \\
\hline DAP & 15.79 & 25.71 & 12.73 & 17.43 \\
\hline NP & 0.00 & 0.00 & 0.00 & 0.00 \\
\hline \multicolumn{5}{|c|}{ Above Recommended } \\
\hline Urea & 10.53 & 28.57 & 54.55 & 38.53 \\
\hline DAP & 0.00 & 5.71 & 10.91 & 7.34 \\
\hline NP & 10.53 & 14.29 & 20.00 & 16.52 \\
\hline \multicolumn{5}{|c|}{ None } \\
\hline Urea & 0.00 & 0.00 & 0.00 & 0.00 \\
\hline DAP & 10.53 & 20.00 & 20.00 & 18.35 \\
\hline NP & 89.47 & 80.00 & 80.00 & 81.65 \\
\hline
\end{tabular}

Source: Survey data, 2011-12

3.2.3 Insects - Pests: A number of insect-pests and diseases attack vegetables. The most common insects were fruit fly, white fly and leaf cutter. The most common disease reported is Downey Mildew. During the discussion with growers it was found that they have applied 2 to 5 sprays of pesticides to control the insectspests. Result indicates that overall 44.04, 45.87, 71.56, 87.16, 77.98 and 86.24 percent respondents applied 23sprays in tomato, Cauliflower, Luffa, carrot, chilies and onion respectively followed by 40.37, 44.96, 24.77, $12.84,19.27$ and 11.93 percent growers applied 3-4 spray in tomato, Cauliflower, Luffa, carrot, chilies and onion respectively.

3.2.4 Vegetable Varietals Distribution: Improved varieties of vegetable play an important role for high production in agriculture crop. The rate of adoption of high yielding varieties determines the speed with which any farming community takes benefits of the efforts of breeders. There are number of varieties of vegetables under cultivation in Pakistan. In the study area only two local varieties are commonly grown, viz; (Luffa and Chilies). Information regarding that overall high $34.86,20.18,81.86,22.02,56.88$ and 55.96 percent respondents planted tomato yaki, Cauliflower Invento, Luffa local, carrot AH-98, chilies local and onion Nasur puri variety respectively planted in the study area. Majority of farmers was unknown from vegetable varieties. Mostly of vegetable farmers planted one variety and some farmers planted two and above two varieties in our field.

3.2.5 Yield : Where as high yield can be achieved by adopting scientific technologies like use of certified seeds, application of recommended doses of fertilizers etc. In industrialized farming methods, each harvest of tomatoes can produce 19,000 to 25,000 pounds of tomatoes per acre, or $650-850$ boxes weighing 30 pounds each [8]. Locally grown tomatoes are derived from farms generally allotting 5/100 an acre to tomato production [9]. Result indicated that in overall, growers received 6814, 6467, 5138, 7641, 701 and $7033 \mathrm{kgs}$ yield per acre in tomato, Cauliflower, Luffa, carrot, chilies and onion respectively, during the study year. Information regarding the onion farmer received high production followed by other vegetable varieties.

3.2.6 Price : There is a wide variation in vegetable prices during the season. There are a number of reasons such as alternative vegetable bearing, supply $\&$ demand in the market, etc. The price in the early harvest session was higher than the mid and late harvest session. The average sale price of rabi and kharif vegetables in mid and late sessions are lower than early season. Information regarding, growers received price was Rs. 21.5, 17, 20.16, 15.76. 71.5 and 15.17 price per $\mathrm{kg}$ in tomato, Cauliflower, Luffa, carrot, chilies and onion respectively, during the study year. Result shows that the overall highest price grower was received from chilies followed by other vegetables in the study area.

3.3.1 Market information: In case of vegetable products, direct marketing system is prevailing. Vegetable growers usually maintain telephonic and personally contacts with commission agents in the required wholesale markets of the country. They send their produce after confirmation of market prices from the commission agents. Information regarding the overall vegetable growers gets marketing information about 44.95 percent from fallow farmers followed by 35.78 percent from commission agent and 19.27 percent from personal visits and through telephonic was found in the study area.

\subsubsection{Cost, Revenue and Return of Vegetable Production}


Locally grown tomatoes are derived from farms generally allotting $5 / 100$ an acre to tomato production $[\mathbf{8}, \mathbf{9}]$. In a comparison of cost production between industrialized tomatoes and locally grown, the researcher compiled averages for each of the two types of industry based on collected reports and budgets. Industrialized tomatoes were found to have an average production cost of $\$ 4085$ per acre $[\mathbf{8}, \mathbf{1 0}, \mathbf{1 1}$. Locally grown cost about $\$ 3912$ per acre to produce, though rarely is an entire acre used in local farming practices [12, 13]. The Center for Sustainable Agriculture Research and Education (SARE) sites that "Production costs tend to be lower in established organic systems because of reduced input costs. One exception to this, perhaps, is labor. Organic farming systems are often more labor intensive because of increased time spent managing weeds and monitoring pests." Information from SARE is accurate with the compiled research, supporting that organic farming is less expensive, but only marginally so.

Costs have been broken down in a variable, fixed and opportunity costs (depreciation and opportunity) costs for production factors that are owned by the vegetable growers. While the variable cost was high from other costs, among them transportation cost was high in the variable cost. The fixed cost was nil due to drought relief from Balochistan government. The acre based cost, revenue and returns of vegetable production are presented in table 5. The gross value of output was composed of the value of production estimated at farm gate price. The expenses incurred on variable and fixed inputs were estimated in terms of imputed and purchased costs. Net income was estimated by deducting total cost from the gross value of output. It was found that the sample farmers had produced vegetable of average gross value amounting Rs. 146501, 109939, 103582, 120422, 50121 and 106691 per acre of tomato, Cauliflower, Luffa, carrot, chilies and onion respectively. The average total cost were estimated as Rs. 86576, 56133, 45401, 53645, 34227 and 61326 /ac, of tomato, Cauliflower, Luffa, carrot, chilies and onion respectively. The average profit of indicates that vegetables growers to obtain the highest profit of carrot growers received from the other major vegetables and lowest profit received chilies grower in the study area.

The results revealed that vegetable growers in study area who cultivate vegetables they obtained net return was Rs. 59925, 53806, 58181, 66777, 15864, 45365 per acre of tomato, cauliflower, Luffa, carrot, chilies and onion, respectively. The returns to per rupee investment and returns to per rupee spent on variable cost were estimated as almost percent was 69.22, 95.85, 128.15, 124.48, 46.35 and 73.97 and 80.15, 115.01, 156.38, 146.92, 71.49 and 89.42 percent respectively of tomato, Cauliflower, Luffa, carrot, chilies and onion respectively.. These returns were relatively high on carrot vegetable than their counterparts.

Table 5. Cost, revenue and net income/return of major vegetable production in 2011-12

\begin{tabular}{|c|c|c|c|c|c|c|}
\hline \multirow[b]{2}{*}{ Operations } & \multicolumn{6}{|c|}{ N/Major Vegetables } \\
\hline & $\begin{array}{r}\text { Tomat } \\
\text { o }\end{array}$ & Cauliflower & Luffa & Carrot & Chilies & Onion \\
\hline Seedbed preparation & 3600 & 4400 & 4000 & 3200 & 3600 & 3600 \\
\hline Seed, seed sowing and ridge making & 4926 & 8760 & 3050 & 5750 & 3800 & 19833 \\
\hline Irrigation & 6216 & 5698 & 1953 & 5698 & 5180 & 5698 \\
\hline Manure \& fertilizer application & 10650 & 8200 & 6200 & 5400 & 5450 & 5900 \\
\hline Plant protection & 3456 & 2947 & 1998 & 900 & 1605 & 1605 \\
\hline Manual \& chemical weeding charges & 1600 & 1058 & 500 & 1183 & 1433 & 1649 \\
\hline Harvesting/Picking & 5750 & 3500 & 3125 & 4000 & 3750 & 3750 \\
\hline $\begin{array}{l}\text { Mark up on investment for } 6 \text { months @ } 11 \% \text { per } \\
\text { annum }\end{array}$ & 4240 & 2666 & 2106 & 2543 & 1524 & 3038 \\
\hline Transportation, packing and marketing charges & 40884 & 13,904 & 17469 & 20096 & 2885 & 11253 \\
\hline A) Total variable cost & 81322 & 51133 & 40401 & 48770 & 29227 & 56326 \\
\hline B) Total fixed cost & $\mathbf{0}$ & 0 & 0 & 0 & 0 & 0 \\
\hline C) Opportunity cost & 5254 & 5000 & 5000 & 4875 & 5000 & 5000 \\
\hline Total cost $(\mathbf{A}+\mathbf{B}+\mathbf{C})$ & 86576 & 56133 & 45401 & 53645 & 34227 & 61326 \\
\hline Gross Revenue & $\begin{array}{r}14650 \\
1 \\
\end{array}$ & 109939 & 103582 & 120422 & 50121 & 106691 \\
\hline Net-income/ac & 59925 & 53806 & 58181 & 66777 & 15864 & 45365 \\
\hline Net-income against variable costs (Rs./ac) & 65179 & 58806 & 63181 & 71652 & 20894 & 50365 \\
\hline Returns/Rs investment (\%) & 69.22 & 95.85 & 128.15 & 124.48 & 46.35 & 73.97 \\
\hline Returns/Rs of variable cost (\%) & 80.15 & 115.01 & 156.38 & 146.92 & 71.49 & 89.42 \\
\hline Benefit Cost Ratio & $1: 1.69$ & $1: 1.96$ & $1: 2.28$ & $1: 2.24$ & $1: 1.46$ & $1: 1.74$ \\
\hline
\end{tabular}

Source: Survey data, 2011-12

3.4.2 Gross margin of different vegetables

The analysis of gross margin is derived from the difference between total revenue and total variable costs. Total variable costs are calculated from the summation of total labor costs, marketing and capital cost. The results 
shows that vegetable growers in study area who cultivate vegetables they obtained highest gross margin Rs. 65179, 58806, 63181, 71652, 20894 and 50365 per acre of tomato, cauliflower, Luffa, carrot, chilies and onion, respectively, Comparing the average gross margin of carrot is higher per acre than the other vegetables in the study area. According to the average total variable costs, there are significant differences between the different vegetables. The highest variable cost was recorded in tomato vegetable and lowest variable costs were reported in chilies vegetable. However, the average total revenue per acre between tomato and other vegetable crops is significantly different in table 6 .

Table 6. Gross margin of hybrid, improved and local vegetable varieties, (Rs/acre.) 2011-12

\begin{tabular}{|c|c|c|c|c|c|c|}
\hline \multirow[b]{2}{*}{ Unit } & \multicolumn{6}{|c|}{ Vegetable Crops } \\
\hline & Tomato & Cauliflower & Luffa & Carrot & Chilies & Onion \\
\hline Total Revenue & 146501 & 109939 & 103582 & 120422 & 50121 & 106691 \\
\hline Total Variable Cost & 81322 & 51133 & 40401 & 48770 & 29227 & 56326 \\
\hline Average gross margin & 65179 & 58806 & 63181 & 71652 & 20894 & 50365 \\
\hline
\end{tabular}

Source: Survey data, 2011-12

\section{Conclusion and Recommendations}

It can be concluded from the above discussion that vegetable has a great potential to become profitable crop as compared to other crops grown in the study area. The yield of vegetable is below than its potential in all the districts, normally the area farmers were using poor traditional cultural practices, where as high yield can be achieved by adopting modern technologies like use of certified seeds, application of recommended doses of fertilizers etc. The main purpose of this study was to conduct detail investigation to know the adoption rate of improved varieties of vegetables among vegetable growers, to conduct the seed market situation analysis, to know the constraints that are being faced by the farmers in adopting the improved varieties and to know the economics of improved varieties on against traditional varieties. It involved gathering of data from primary as well as secondary sources, particularly on input use, management practices and other related issues. The production system was found to follow traditional practices resulting in low production as compared to the potential yield. Causes of low yield identified lack of knowledge of hybrid/improved variety, inadequate use of fertilizer and weedicide application.

Information regarding the onion farmer received high production followed by other major vegetables. There is a wide variation in vegetable prices during the season. There are a number of reasons such as alternative vegetable bearing, supply $\&$ demand in the market, etc. The price in the early harvest session was higher than the mid and late harvest session. Result indicates that the average sale price of Rabi and Kharif vegetables in mid and late sessions are lower than early season. Awareness of marketing as a concept and is vital and dynamic element in economic development and has greatly increased in the developing countries during the last three decades. The improvement in the functioning of commodity markets as well as the improved performance of the marketing system is now generally recognized as important, strategic elements in agricultural and economic development. Changes of attitude to marketing have come about particularly during the last decade, when many developing countries have had to undergo stringent economic reforms. In most developing countries, government policies and programme directed at agricultural marketing have been based more on preconceived ideas about the nature of the existing marketing system than on accurate information and economic analysis.

Vegetable growers have to adopt better management practices and seek to adopt scientific recommendations from local and available sources such as, research stations, progressive growers and extension agents. Particularly, they require timely planting of vegetable and appropriate use of fertilizer and weedicide. Non-availability of improved, disease - free, certified seed of high yielding vegetable varieties is the main constraint in large-scale vegetable production in Balochistan. It is highly recommended of the involvement of privates sector to provide improved certified seed to the vegetable growers. Load shedding was also found a problem. The period of load shedding ranges from 10-15 hours in 24 hours. The duration of load shedding must be reduced. The rainwater losses are high in Loralai particular and Balochistan in general, so construction of dams and mini-dams can minimize the loss of water and increase underground water table.

\section{References}

[1] Khushk A.M and M.I.Lashari 2004, Improving the marketing system of vegetables, DAWN - Business_09 August, 2004.htm http://www.dawn.com/copyright.htm 
[2] Moustafa, A, 2007, Protected Agriculture: A Different Greenhouse Effect, Coordinator of ICARDA's Arabian Peninsula Regional Program, based in Dubai, UAE. Issue No.24 June 2007

[3] Government of Balochistan (2010-11). Agricultural Statistics Balochistan. Directorate of Reporting Services, Agricultural Department Balochistan, Quetta.

[4] Biz. (2002) The Break-Even Point, Bristol, UK: University of Bristol, Institute for Learning and Research Technology, (accessed June, 2006).http://www.bized.ac.uk/virtual/vla/theories/break even.htm

[5] Hofstrand, D. (2005) Farm Analysis Terms. Iowa, USA: Iowa State University, (accessed June, 2006).http://www.extension.iastate.edu/agdm/wholefarm/html/c1-05.html

[6] Markus, L. 2006. Farm and Agribusiness Management. Moscow, USA: University of Idaho , Department of Agricultural Economics and Rural Sociology, (accessed June, 2006). http://courses.ag.uidaho.edu/aers/agecon278/Fall05/Chap10.pdf\#search

[7] FAO. (2006). Training Manual on Farm Planning and Management for Trainers of Extension Workers. USA: Food and Agriculture Organization of United Nation, Economics Social Department, $\begin{array}{lll}\text { Organization } & \text { of } & \text { United }\end{array}$ www.fao.org/ag/Ags/subjects/en/farmMgmt/pdf/HANDOUTI.pdf (accessed June, 2006).

[8] Diver, S., Kuepper, G., Born, H. (1999). Tomato Acreages, Yields, Economics, and Harvest. National Sustainable Agriculture Information http://attra.ncat.org/attra-pub/tomato.html

[9] Hood, K., Walden, C. (2005). Budget for Greenhouse Tomatoes. Extension Service Mississippi State Service United States

[10] Agricultural Research Service. (2000). United Agriculture.http://www.ars.usda.gov/is/np/mba/oct98/tomato.htm

[11] McCraw, D., Motes, J., Schatzer, R. Commercial Production of Fresh Market Tomatoes. Okalahoma Cooperative Extension Service.

[12] New Jersey Agricultural Experiment Station. (1996). Organic Production Practices. http://aesop.rutgers.edu/ farmmgmt/ne-budgets/organic/Tomatoes-FreshMarket.html

[13] Estes, E., Kleese, T., Lauffer, L. (2003). North Carolina Organic Vegetable Production Cost Study. Department of Agricultural and Resource Economics. http://www2.ncsu.edu/unity/lockers/project/arepublication/AREno31.pdf 